\title{
Response to the letter to the editor regarding article by Hussein et al. DOI: 10.1007/s00405-014-3309-7
}

\author{
Wael Khamis Hussein
}

Received: 3 December 2014/ Accepted: 15 December 2014/Published online: 9 January 2015

(C) Springer-Verlag Berlin Heidelberg 2015

\section{Dear Editor,}

I received the letter that was sent by Dr. Ozucer and I can say that I was kind of surprised that a fellow surgeon had the same idea. Well, I assure you that none of the authors knew at any stage of the study or article submission that the submitted work of Dr. Ozucer was ongoing or even published; otherwise, we would have taken it in consideration. In fact as you already know, the study started in December 2011 and during the study period in several occasions, the idea and steps were taught to fellow doctors.

I recall that during the period of 23-25 October, 2012, the Fourth international annual meeting RHINOALEX was held in Alexandria (Egypt). I presented the idea of the ongoing research "Autospreader Flap Technique demonstration and modification" in that conference. I am attaching the website of the conference on which a download link of the program brochure could be seen (Check page 15 of the brochure). I would believe that the honorable international speakers and many others who attended would confirm the occasion and among them I recall; Doctor Alessandro Varini, Trieste (Italy), Professor Hisham Khalil, Consultant ENT at Derriford and the Plymouth Nuffield Hospitals (UK), Professor Usama Hadi, Clinical Professor American University of Beirut Medical
Center (Lebanon) (Conference website; http://rhinoalex. com/?q=page/rhinoalex2012).

Dear Editor, I had the honor to be a research fellow of the University of Michigan (USA) back in 2006. During that period, I was lucky to be mentored by Professor Shan Baker (Professor and Chief of the Facial Plastic and Reconstructive Surgery Unit, Otolaryngology Department). $\mathrm{He}$ is also an author of the original Autospreader Flap Technique (URL attached below). Professor Baker supervised my work during the stay and I am confident that he would confirm my researching methods' integrity and credibility (The Autospreader Flap in Reduction Rhinoplasty http://archfaci.jamanetwork.com/article. aspx? articleid=223 675).

Reading the article of Dr. Ozucer, I can see the similarities he claims and I can also see that he used different methods of assessment of his work than we have used in ours. I am glad that all the methods either published in his work or ours would indicate that the Modified Autospreader Flap is a valuable technique for reconstructing the nasal valve and that is my main concern, after all, we all seek the improvement of the quality of life of our patients.

This reply refers to the comment available at doi:10.1007/s00405-014-3455-y.

W. K. Hussein $(\bowtie)$

Facial Plastic Surgery Division, Otolaryngology Department, Alexandria Faculty of Medicine, Alexandria, Egypt

e-mail: wael.khamis@alexmed.edu.eg 